\title{
Perancangan Sistem Monitoring Skripsi dengan Metode Web Engineering (Studi Kasus: Fakultas Ilmu Komputer Universitas Katolik Santo Thomas) Andy Paul Harianja ${ }^{1}$, Intan Sari Sembiring Kembaren ${ }^{2}$ \\ ${ }^{1,2}$ Universitas Katolik Santo Thomas Jl. Setia Budi No. 479 F Medan, 061-821016, Indonesia
}

\begin{tabular}{l} 
ARTICLE INFORMATION \\
\hline Received: September 5, 2019 \\
Revised: September, 22, 2019 \\
Available online: Oktober, 20, 2019 \\
KEYWORDS \\
\hline sistem monitoring, web engineering, skripsi \\
CORRESPONDENCE \\
\hline E-mail: apharianja@ gmail.com \\
\hline
\end{tabular}

\begin{abstract}
A B S T R A K
Skripsi merupakan suatu karya tulis ilmiah yang disusun oleh seorang mahasiswa jenjang S1 yang membahas suatu permasalahan atau fenomena dalam bidang ilmu tertentu dengan menggunakan kaidah-kaidah yang berlaku. Sistem monitoring skripsi adalah sistem yang dapat digunakan untuk melihat semua data-data bimbingan mahasiswa secara detail. Pada Fakultas Ilmu Komputer Universitas Katolik Santo Thomas Sistem monitoring skripsi masih dilakukan secara manual yaitu data bimbingan mahasiswa dituliskan pada kertas dan disimpan pada suatu draft. Tujuan penelitian adalah merancang sistem monitoring skripsi dengan metode web enginnering untuk menghubungkan antara mahasiswa dan dosen pembimbing agar lebih mudah melakukan bimbingan dan juga untuk Kepala Program Studi (Kaprodi) agar dapat memantau semua mahasiswa yang bimbingan. . Sistem ini dikembangkan dengan menggunakan bahasa pemograman PHP dan MySQL.
\end{abstract}

\section{LATAR BELAKANG}

Fakultas Ilmu Komputer Universitas Katolik Santo Thomas monitoring skripsi masih dilakukan secara manual yaitu mahasiswa bertemu langsung dengan dosen pembimbingnya untuk berkonsultasi tentang skripsi. Kadang kala mahasiswa sulit bertemu dengan dosen pembimbing yang memiliki jadwal yang sibuk sehingga mahasiswa harus selalu ke kampus untuk menemui dosen pembimbing. Dosen pembimbing juga kesulitan untuk memantau perkembangan mahasiswa bimbingannya karena harus melihat satu persatu di buku bimbingan dan dikarenakan monitoring skripsi masih manual memungkinkan dosen lupa mahasiswa yang hampir selesai dan mahasiswa yang masih terlambat menyusun skripsi. Kaprodi juga kesulitan untuk memantau sejauh mana hasil pengerjaan mahasiswa yang sudah bimbingan karena harus bertanya dahulu kepada semua dosen pembimbing masing-masing. Monitoring skripsi secara manual ini juga memiliki dampak bagi mahasiswa yang akan mengajukan judul skripsi karena kebanyakan topik skripsi yang diajukan sudah pernah ada dibawakan oleh mahasiswa yang lama. Mahasiswa kesulitan untuk mengetahui topiktopik apa saja yang sudah pernah diajukan oleh mahasiswa yang pernah bimbingan.

Web Engineering adalah sebuah proses yang digunakan untuk menciptakan web aplikasi berkualitas tinggi. Atribut yang akan ditemui dalam web aplikasi di antaranya adalah intensitas web yaitu seberapa banyak intensitas web dalam melayani klien, concurrency adalah seberapa banyak jumlah user yang akan mengakses dalam satu waktu, unpredictable load adalah jumlah pengakses yang tidak diperhitungkan, performance adalah kehandalan web dalam melayani klien, availability adalah ketersediaan web sepanjang waktu dan continuous evolution yaitu update secara terus menerus.[1]

Penelitian Putu Ramayasa, Ida Bagus Ketut S A. yang diterbitkan pada tahun 2015 yang berjudul "Perancangan sistem monitoring Pengerjaan Skripsi Pada Stmik Stikom Bali Berbasis Web". Pada penelitian ini dirancang sistem monitoring skripsi yang digunakan oleh Dosen Pembimbing, Pihak Admin dan Mahasiswa [2]. Begitu juga dalam peneltiian Agil Assagaff dan Adelina Ibrahim yang diterbitkan pada tahun 2018 yang berjudul "Sistem Monitoring Ujian Skripsi Pada Program Studi Teknik Informatika UMMU". Pada penelitian tersebut Sistem digunakan mempermudah dosen untuk menginput data mahasiswa dan langsung bisa menentukan lulus atau tidaknya mahasiswa yang bersangkutan dalam mengikuti ujian proposal dan skripsi [3], dan penelitian oleh Hasdiana Nurjamiah yang diterbitkan pada Tahun 2017 yang berjudul "Perancangan Sistem Informasi Manajemen Skripsi Pada Program Studi Sistem Informasi (Studi Kasus: STTH-Medan)".Pada penelitian ini Sistem dirancang untuk membantu program studi dalam pengaturan hubungan baik antara pembimbing dengan mahasiswa, mahasiswa dengan program studi maupun program studi dengan dosen pembimbing [4].

Sistem Monitoring adalah suatu jaringan kerja dari prosedur-prosedur yang saling berhubungan, berkumpul bersama-sama untuk melakukan suatu kegiatan atau untuk menyelesaikan suatu sasaran tertentu. Sistem monitoring merupakan suatu proses untuk mengumpulkan data dari berbagai sumber daya[5]. Monitoring adalah pemantauan suatu proyek atau program yang sedang berjalan untuk membantu pengambilan keputusan manajemen program/proyek.

\section{METODE PENELITIAN}

Dalam menyelesaikan sebuah penelitian perlu membuat sebuah langkah dan tahapan agar penelitian tersebut sesuai dengan kebutuhan dan selesai tepat waktu, adapun metodologi penelitian yang dilakukan dalam penelitian ini adalah[6]:

1. Observasi

Metode Pengumpulan data dengan cara mengamati langsung sistem monitoring yang sedang berjalan di Fakultas Ilmu Komputer

2. Studi Pustaka

Metode pengumpulan data dengan cara mencari referensi dari buku dan jurnal yang terkait dengan penelitian.

3. Wawancara

Metode Pengumpulan data dengan cara tanya jawab kepada pihak-pihak yang berhubungan dengan penelitian.

4. Pengujian dengan menggunakan Metode Web Engineering

Perancangan Sistem Monitoring Skripsi dengan Metode Web Engineering (Studi Kasus: Fakultas Ilmu Komputer

Universitas Katolik Santo Thomas). Oleh: Andy Paul Harianja, Intan Sari Sembiring Kembaren 
Web Engineering adalah proses yang digunakan untuk menciptakan web aplikasi berkualitas tinggi. Atribut yang akan ditemui dalam web aplikasi diantarnya adalah intensitas web yaitu seberapa banyak intensitas web dalam melayani klien, concurrency adalah seberapa banyak jumlah user yang akan mengakses dalam satu waktu, unpredictable load adalah jumlah pengakses yang tidak diperhitungkan, performance adalah kehandalan web dalam melayani klien, availability adalah ketersediaan web sepanjang waktu dan continuous evolution yaitu update secara terus menerus. Metode web engineering terdapat 5 (lima) tahapan untuk dapat mengembangkan suatu perangkat lunak[1], [7].

1. Customer communication.

Komunikasi dalam hal ini terutama terkonsentrasi pada dua hal, analisa bisnis dan perumusan. Analisa bisnis akan mendefinisikan hal-hal apa saja yang akan termuat di dalam aplikasi web, misalnya pengguna web yang akan dibangun, perubahan potensial dalam lingkungan bisnis, integrasi antara web yang akan dibangun dengan situasi bisnis perusahaan, maupun database perusahaan.

2. Planning

Yaitu tahap penggabungan requirement (kebutuhan) dan informasi dari user dan perencanaan teknis serta menanggapi respon (tanggapan) dari user. Perencanaan teknis dilakukan dengan mengidentifikasi perangkat lunak maupun perangkat keras apa saja yang dibutuhkan. Perencanaan terdiri dari pendefinisian pekerjaan dan target waktu atas pekerjaan maupun sub pekerjaan yang ditentukan.

3. Modelling

Tujuan dari aktivitas ini adalah untuk menjelaskan hal-hal apa saja yang memang diperlukan / dibutuhkan pada aplikasi yang akan dibangun dan solusi yang ditawarkan yang diharapkan dapat menjawab apa yang tersirat dari hasil-hasil analisa dan pengumpulan data.

4. Construction

Pembangunan aplikasi web memadukan antara perkembangan teknologi dengan tools pengembangan web yang telah ada, artinya memilih tools yang efektif namun tetap dapat menyesuaikan dengan teknologi yang berkembang saat ini.

5. Deployment

Aplikasi web diciptakan untuk dapat berguna bagi kebutuhan pekerjaan, dapat dioperasikan oleh end-user, dan kemudian dilakukan evaluasi secara berkala, memberi masukan-masukan kepada team pengembang dan apabila diperlukan akan dilakukan modifikasi pada aplikasi web tersebut.

\subsection{Perancangan Sistem}

\section{HASIL DAN PEMBAHASAN}

Perancangan sistem dapat didefinisikan sebagai penggambaran, perencanaan, dan pembuatan sketsa atau pengaturan dari beberapa elemen terpisah ke dalam satu kesatuan yang utuh dan berfungsi [8]. Perancangan sistem ini merupakan gambaran tentang sistem yang akan dibangun.

1. Use Case Diagram

Didalam perancangan sistem ini terdapat 3 aktor yang memiliki aktivitas-aktivitas yang berbeda-beda. Adapun ketiga actor tersebut ialah admin, kaprodi, dosen dan mahasiswa. Gambar use case diagram sistem monitoring skripsi seperti pada gambar 1 .

2. Class Diagram

Class Diagram secara khas meliputi: Kelas (Class), Relasi Assosiations, Generalitation dan Aggregation, atribut (Attributes), operasi (operation/method) dan visibility, tingkat akses objek eksternal kepada suatu operasi atau atribut. Hubungan antar kelas mempunyai keterangan yang disebut dengan Multiplicity atau Cardinality [9]. Gambar class diagram sistem monitoring skripsi adalah seperti pada gambar 2 di bawah.

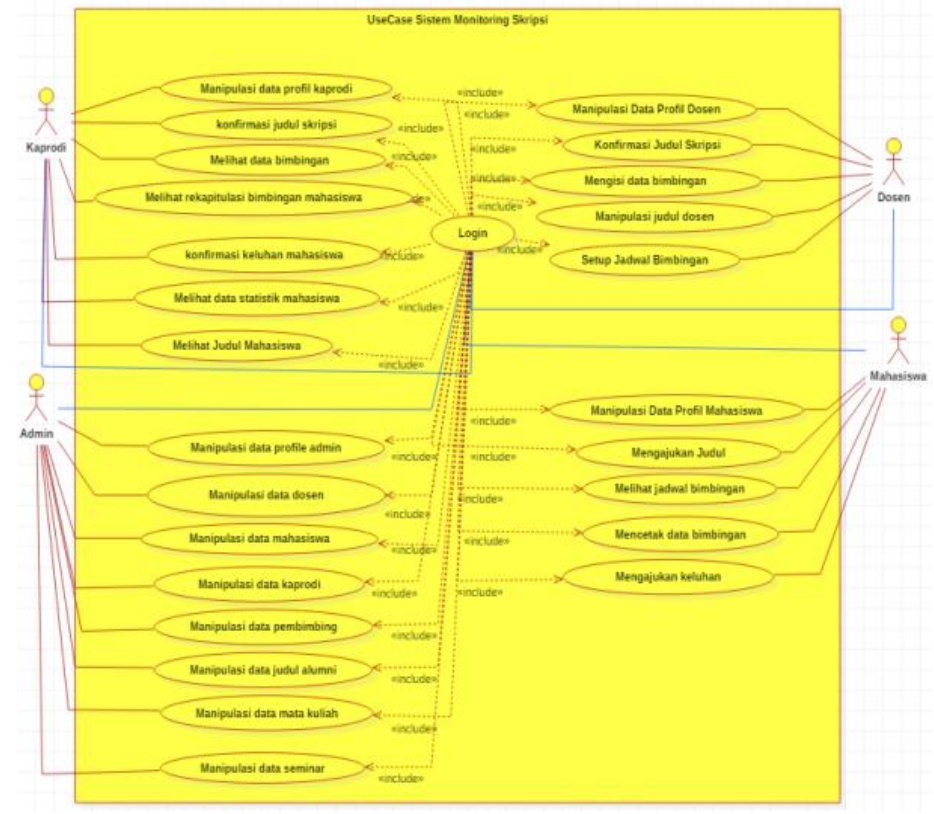

Gambar 1. Use Case Diagram Sistem Monitoring Skripsi 


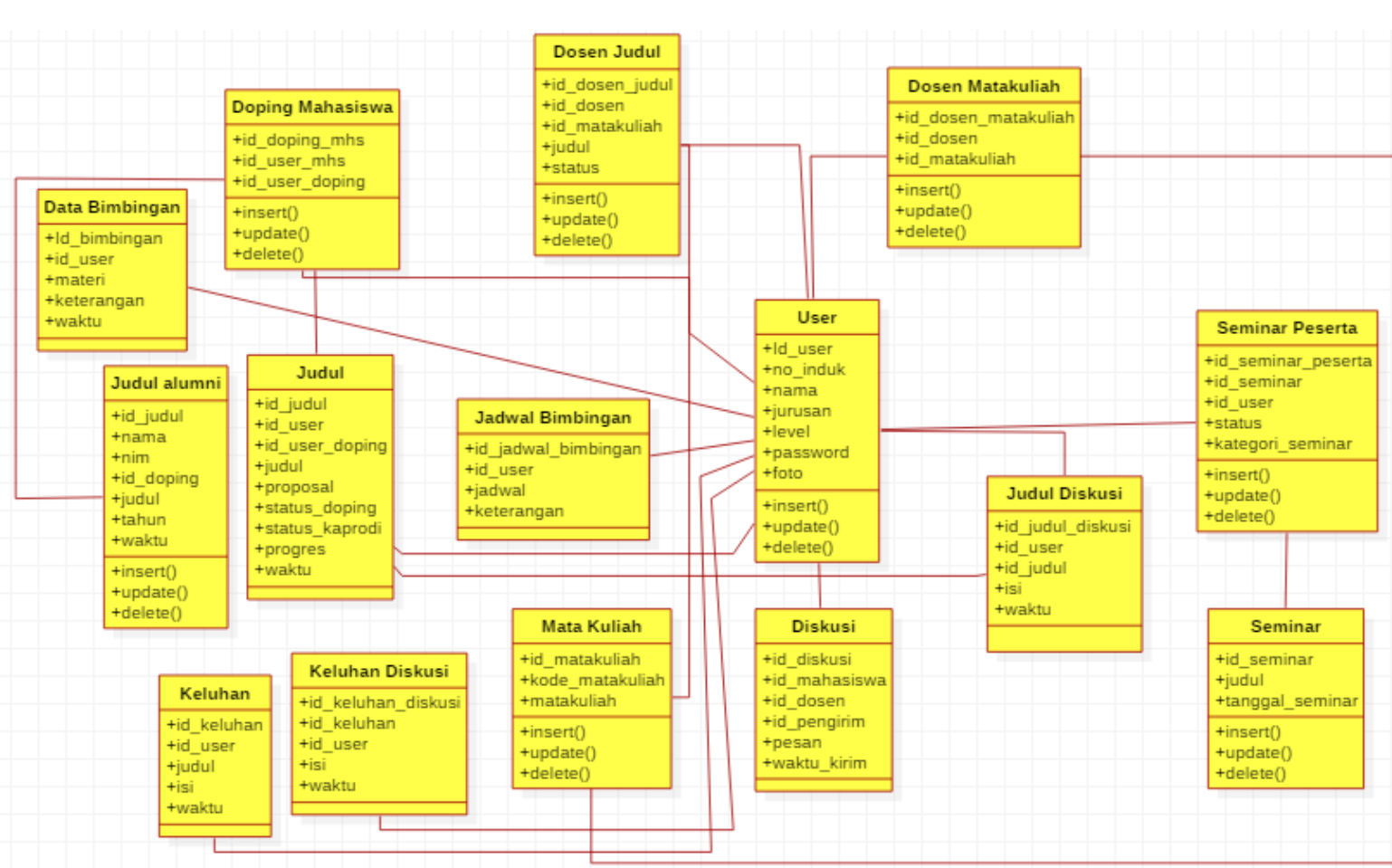

Gambar 2. Class Diagram Sistem Monitoring Skripsi

\subsection{Implementasi}

Sistem yang telah dibangun harus telah disetujui dan sesuai dengan perancangan yang telah dibuat sebelumnya.

1. Halaman Beranda

Tampilan halaman beranda merupakan tampilan awal dari sistem monitoring ini yang menyediakan fitur-fitur apa saja yang tersedia seperti pada gambar 3 di bawah ini.

\section{UNIKA BERANDA PANDUAN JUDUL DOSEN SEMINAR LOGIN}

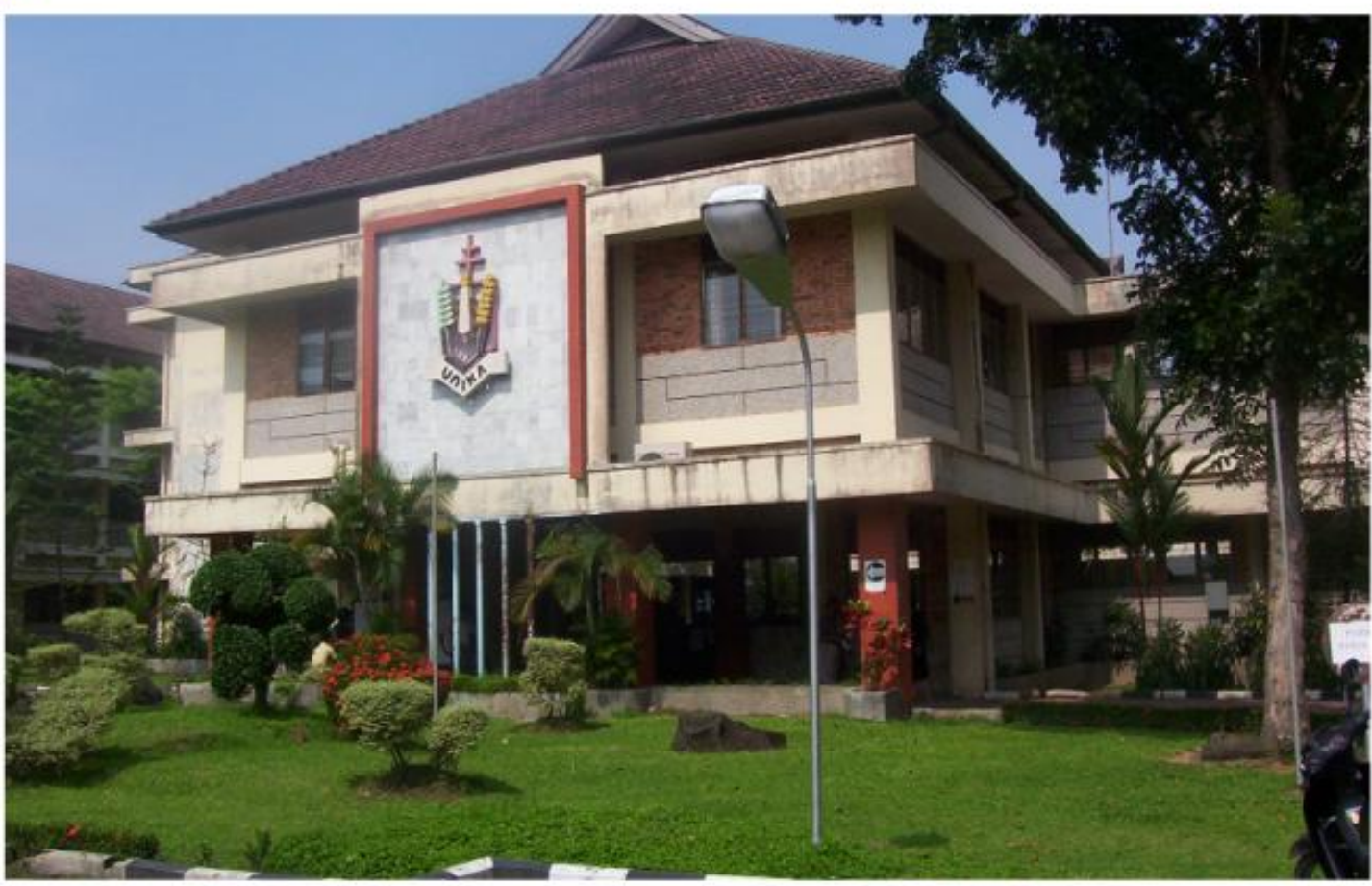

Gambar 3. Halaman Beranda

2. Menu Login

Menu ini terdiri dari form login ke dalam sistem yang dapat digunakan untuk semua user, seperti pada gambar 4 di bawah ini. 
- UNIKA

geranda panduan Judul dosen seminar Login

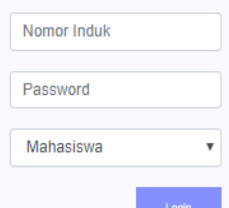

Gambar 4. Menu Login

3. Menu Profile Dosen

Menu ini dapat digunakan dosen untuk memanipulasi data dosen, seperti pada gambar 5 di bawah ini.

- UNIKA
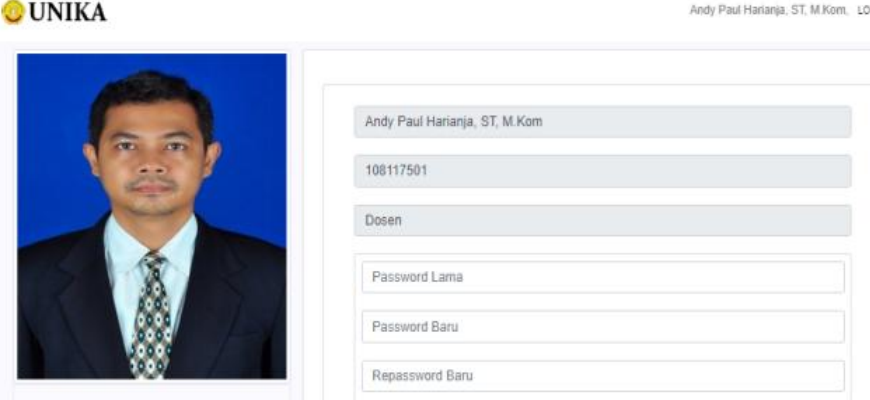

Protile

Juoul

Jadwal Bimbingan
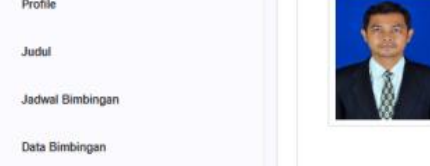

Choose filie No file chosere

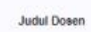

Gambar 5. Menu Profile Dosen

4. Menu Profile admin

Menu ini dapat digunakan untuk memanipulasi data admin, seperti pada gambar 6 di bawah ini.

OUNIKA
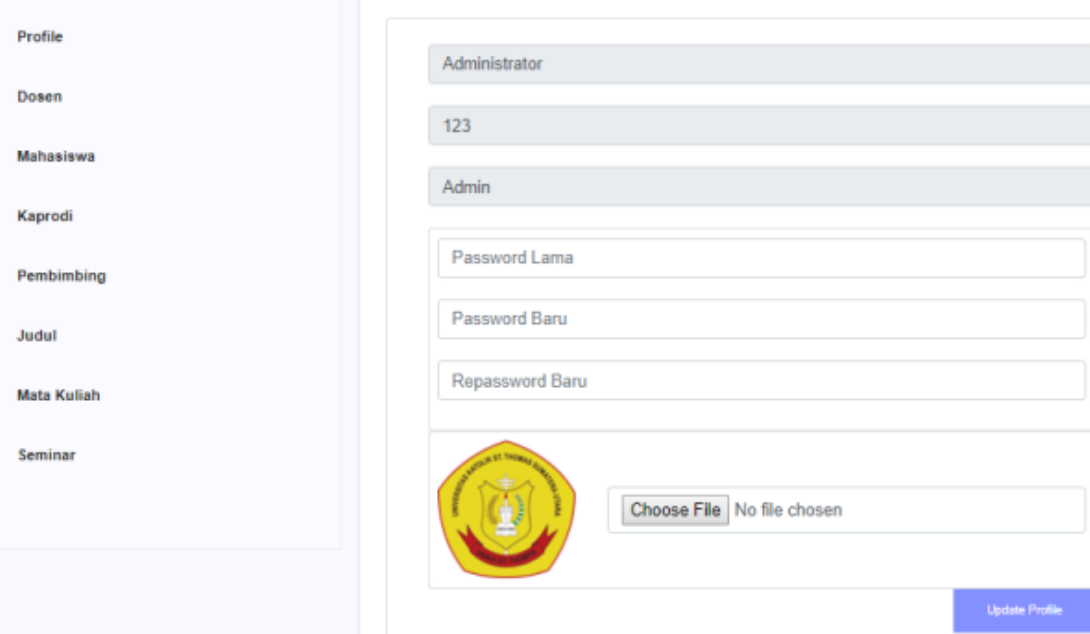

Gambar 6. Menu profile admin

5. Menu profile mahasiswa

Menu ini digunakan untuk memanipulasi data profile mahasiswa. Gambar 7 di bawah ini adalah merupakan tampilan menu profile mahasiswa. 
- UNIKA



Gambar 7. Menu Profile Mahasiswa

6. Halaman Output Data Bimbingan

Data bimbingan mahasiswa dapat dicetak kedalam bentuk pdf. Halaman output data bimbingan seperti pada gambar 8 di bawah ini.

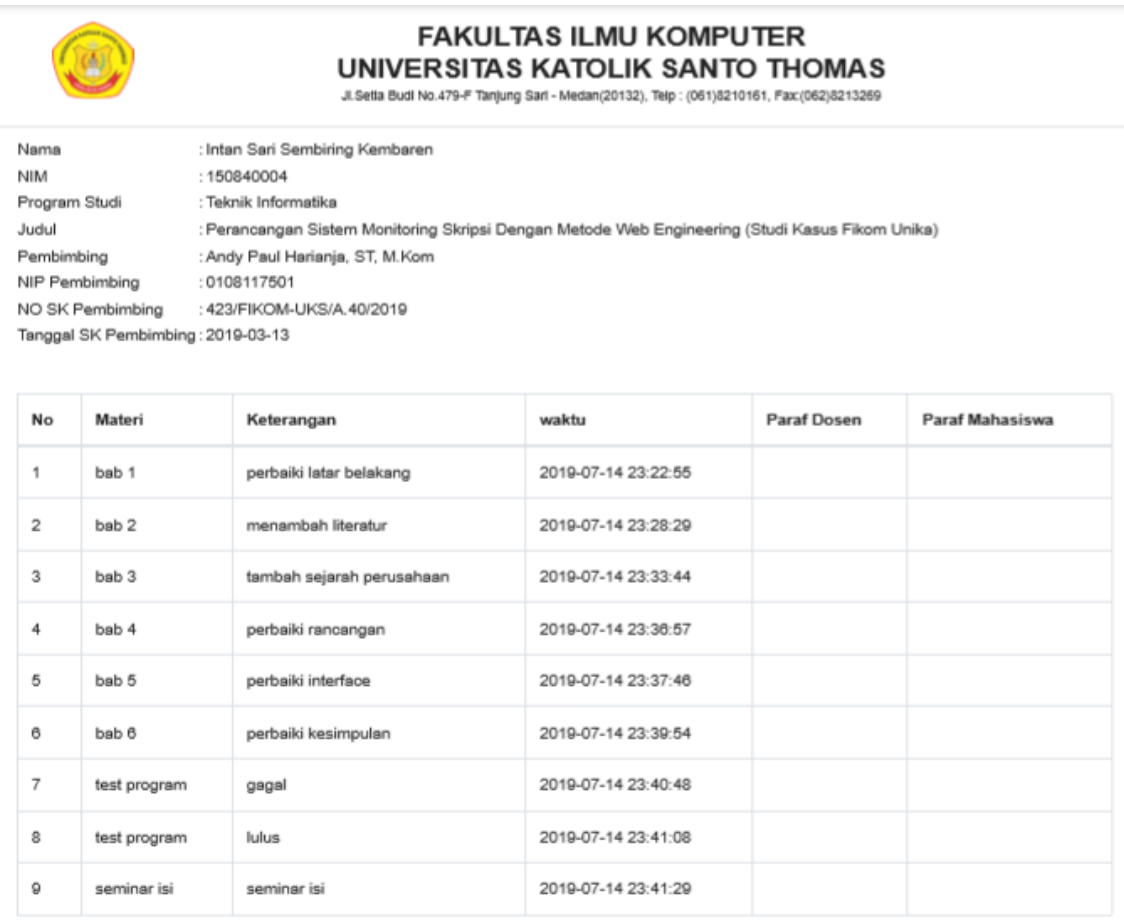

Gambar 9. Halaman Output Data Bimbingan

\section{KESIMPULAN}

Berdasarkan hasil penelitian yang sudah dilakukan, maka dapat diambil beberapa simpulan sebagai berikut:

1. Kaprodi dapat memonitoring skripsi mahasiswa dengan melihat data bimbingan mahasiswa, dapat mengkonfirmasi judul skripsi mahasiswa dan dapat melihat statistik progres bimbingan skripsi mahasiswa dan juga kaprodi dapat membantu mahasiswa yang memiliki keluhan selama proses bimbingan skripsi.

2. Dosen dapat mengatur jadwal bimbingan dan juga mengisi data bimbingan mahasiswa.

3. Mahasiswa dapat melihat jadwal bimbingan, dapat melihat data bimbingan dan mencetak data bimbingan. Mahasiswa juga dapat mengajukan keluhan selama bimbingan kepada kaprodi.

4. Memudahkan mahasiswa dalam memilih judul skripsi yang ditawarkan oleh masing-masing dosen.

\section{DAFTAR PUSTAKA}

[1] Resa, "Web Engineering «Rekayasa Perangkat Lunak -05130-," Rekayasa Perangkat Lunak - 95130, 1991. [Online]. Available: https://resaseptiari05130.wordpress.com/2011/10/31/web-engineering/. [Accessed: 01-May-2020].

[2] R. I. Putu and A. I. B. K. Surya, "Perancangan Sistem Monitoring Pengerjaan Skripsi Pada Stmik Stikom Bali Berbasis Web," Proceedings Konferensi Nasional Sistem dan Informatika, 2015. [Online]. Available: http://ejournal.stikombali.ac.id/index.php/knsi/article/view/462. [Accessed: 01-May-2020]. 
[3] A. Ibrahim and A. Assagaf, "Sistem Monitoring Ujian Skripsi pada Program Studi Informatika UMMU," Universitas (Stuttg)., vol. 1, no. 1, 2018

[4] Hasdiana and Nurjamiyah, "PERANCANGAN SISTEM INFORMASI MANAJEMEN SKRIPSI PADA PROGRAM STUDI SISTEM INFORMASI (STUDI KASUS: STTH-MEDAN),” KOMIK (Konferensi Nas. Teknol. Inf. dan Komputer), vol. I, no. 1, pp. 37-44, 2017.

[5] E. Lestariningsih, E. Ardhianto, W. T. Handoko, E. Supriyanto, and S. L. R. A, "Visualisasi Data Penduduk Berbasis Web di Kelurahan Mranggen Kecamatan Mranggen Kabupaten Demak menggunakan Highcart 5.0.6,” J. Teknol. Inf. Din., vol. 21, no. 2, pp. 146-153, 2016.

[6] Sugiyono, Metode Penelitian Kuantitatif, Kualitatif dan R\&D. Bandung: PT Alfabet, 2016.

[7] N. Hadinata and D. Udariansyah, "IMPLEMENTASI METODE WEB ENGINEERING DALAM MAHASISWA BARU DAN TES ONLINE,” 2013.

[8] P. Ritonga, "Pengertian Unified Modeling Language ( UML ) dan Modelnya Menurut Pakar dan Ahli," 2015. [Online]. Available: https://bangpahmi.com/pengertian-unified-modeling-language-uml-dan-modelnya-menurut-pakar-dan-ahli/. [Accessed: 24-Dec-2019].

[9] I. Zufria, "Pemodelan Berbasis UML (Unified Modeling Language) dengan Strategi Teknik Orientasi Objek User Centered Design(UCD) dalam Sistem Administrasi Pendidikan,” Processor, Jan. 2013. 